and 1983$) 41 \%$ of 317 patients who were thought to have died from paracetamol alone did so either outside, or on arrival at, hospital. In 1979, 61 of 65 such patients who died outside hospital had no evidence of hepatic necrosis at necropsy; in 1983, 58 of 65 patients had no evidence of liver damage. Furthermore, in most of these cases the circumstantial evidence pointed towards other drugs that had not been sought analytically.

Secondly, treatment of patients may be wrongly or inadvertently withheld. There are a few clinical chemistry departments who still refuse to undertake emergency measurement of plasma paracetamol concentrations. Less commonly, patients may present atypically after an overdose -for example, with abdominal pain, coma, and/or metabolic acidosis. Finally, a few patients, despite being aware of the consequences, deliberately present late to hospital or conceal their history of overdose.

The management of paracetamol poisoning is now well established. Patients who present to hospital within four hours of taking at least $10 \mathrm{~g}$ paracetamol should undergo gastric lavage. Children aged less than 6 years tend to swallow only small amounts of paracetamol, and gastric lavage is probably unnecessary. In neither adults nor children has the value of syrup of ipecacuanha been established. Moreover, ipecacuanha induces symptoms indistinguishable from those that sometimes occur early in paracetamol poisoning.

When four hours or more have elapsed after the overdose the plasma concentration of paracetamol should be measured. Specific treatment is required if the concentration falls above a line drawn between $1.32 \mathrm{mmol} / \mathrm{l}(200 \mathrm{mg} / \mathrm{l})$ at 4 hours and $0.33 \mathrm{mmol} / \mathrm{l}(30 \mathrm{mg} / \mathrm{l})$ at 15 hours after the overdose. Acetylcysteine should be given intravenously, or, alternatively, oral methionine may be given unless the patient is either vomiting or unconscious (usually the result of taking another drug). Both agents are of little value more than 15 hours after overdose. Patients at risk of hepatic failure should receive a prophylactic infusion of dextrose to prevent hypoglycaemia, and established hepatic or renal failure should be managed conventionally.

T J MEREDITH Senior Registrar in Medicine

Guy's Hospital,

London SE1 9RT

L F PRESCOTT

Professor of Clinical Pharmacology

University of Edinburgh,

Edinburgh EH3 9YW

J A VALE

Dudley Road Hospital,

Birmingham B18 7QH

Correspondence to: Dr Meredith.

1 Davidson DGD, Eastham WN. Acute liver necrosis following overdose of paracetamol. $\mathrm{Br} \mathrm{Med} \mathcal{f}$ 1966;ii:497-9.

2 Thomson JS, Prescott LF. Liver damage and impaired glucose tolerance after paracetamo overdosage. $B r$ Med $\mathcal{F} 1966$;ii:506-7.

3 Meredith TJ, Vale JA. Epidemiology of analgesic overdose in England and Wales. Hum Toxicol 1984;3:61S-74S

4 Office of Population Censuses and Surveys. Mortality statistics-accidents and violence. Series DH4 (table 10). London: HMSO, 1984

Meredith TJ, Newman B, Goulding R. Paracetamol poisoning in children. Br Med $\mathcal{f}$ 1978;ii: 478-9.

6 Prescott LF, Proudfoot AT, Cregeen RJ. Paracetamol-induced acute renal failure in the absence of fulminant liver damage. $\mathrm{BrMed} \mathcal{f}$ 1982;284:421-2.

7 Zezulka A, Wright N. Severe metabolic acidosis early in paracetamol poisoning. Br Med $\mathcal{f}$ 1982;285:851-2.

8 Vale JA, Meredith TJ. Metabolic acidosis in paracetamol poisoning. Br Med f 1982;285:1208.

9 Record CO, Iles RA, Cohen RD, Williams R. Acid-base and metabolic disturbances in fulminan hepatic failure. Gut 1975;16:144-9.

10 Zabrodski RM, Schnurr LP. Anion gap acidosis with hypoglycaemia in acetaminophen toxicity Ann Emerg Med 1984;13:956-9.
11 Prescott LF, Illingworth RN, Critchley JAJH, Stewart MJ, Adam RD, Proudfoot AT Intravenous $\mathrm{N}$-acetylcysteine: the treatment of choice for paracetamol poisoning. $\mathrm{Br} \mathrm{Med}$ 1979;ii: 1097-100

12 Miner DJ, Kissinger PT. Evidence for the involvement of N-acetyl-p-quinoneimine in acetaminophen metabolism. Biochem Pharmacol 1979;28:3285-90.

13 Mitchell JR, Jollow DJ, Potter WZ, Gillette JR, Brodie BB. Acetaminophen-induced hepatic necrosis IV. Protective role of glutathione. F Pharmacol Exp Ther 1973;187:211-7.

14 Devalia JL Ogilvie RC, McLean AEM. Dissociation of cell death from covalent binding of paracetamol by flavones in a hepatocyte system. Biochem Pharmacol 1982;31:3745-9.

5 Devalia JL, McLean AEM. Covalent binding and the mechanism of paracetamol toxicity. Biochem Pharmacol 1983;32:2602-3.

6 Prescott LF, Newton RW, Swainson CP, Wright N, Forrest ARW, Matthew H. Successful treatment of severe paracetanol overdosage with cysteamine. Lancet 1974;i:588-92.

17 Harvey F, Goulding R. Action of cysteamine in paracetamol poisoning. Lancet 1974;ii: 1082.

18 Revesz L, Modig H. Cysteamine-induced increase of cellular glutathione level:a new hypothesis of the radioprotective mechanism. Nature 1965;207:430-1.

19 Beatty P, Reed BJ. Influence of cysteine upon the glutathione status of isolated rat hepatocytes. Biochem Pharmacol 1981;30:1227-30.

20 Prescott LF, Park J, Ballantyne A, Adriaenssens P, Proudfoot AT. Treatment of paracetamo (acetaminophen) poisoning with n-acetylcysteine. Lancet 1977;ii:432-4.

21 Rumack BH, Peterson RG. Acetaminophen overdose: incidence, diagnosis and management in 416 patients. Pediatrics 1978;62(suppl):898-903S.

22 Bateman DN, Woodhouse $\mathrm{KW}$, Rawlins MD. Adverse reactions to $\mathrm{N}$-acetylcysteine. Hum Toxicol 1984;3:393-8.

23 Mant TGK, Tempowski JH, Volans GN, Talbot JCC. Adverse reactions to acetylcysteine and effects of overdose. Br Med f 1984;289:217-9.

24 Moldeus P. Use of isolated cells in the study of paracetamol metabolism and toxicity: capacity of conjugated pathways and glutathione homeostasis. In: Davis $M$, Tredger JM, Williams R, eds. Drug reactions and the liver. London: Pitman Medical, 1981:144-56.

25 Vale JA, Meredith TJ, Goulding R. Treatment of acetaminophen poisoning. The use of orat methionine. Arch Int Med 1981;141:394-6.

26 Meredith TJ, Vale JA, Goulding R. The epidemiology of acute acetaminophen poisoning in England and Wales. Arch Intern Med 1981;141:395-400

27 Vale JA, Buckley BM, Meredith TJ. Deaths from paracetamol and dextropropoxyphene (Distalgesic) poisoning in England and Wales in 1979. Hum Toxicol 1984;3(suppl):135-43S

\section{The need for a public health alliance}

Last week in a room containing not a molecule of smoke about 50 people interested in public health got together and plotted the formation of a public health alliance. All sorts of factions were represented, including a smattering of doctors, several people from local government, and the Health Education Council, which had sponsored the meeting. But do we need such an organisation, and if we do what should be its aims and structure?

The case for some organisation is strong. Firstly, many issues are debated without the public health aspect being considered. For instance, the possible health consequences of privatising water supplies received very little attention; rarely do we hear anything of how deterioration in sewers may harm health; and nor did anybody seem even to notice the health implications of recent changes in public transport. Secondly, there are issues on which the health message does not come through nearly as strongly as it should. These include poverty, unemployment, housing, and homelessness. Thirdly, on some subjects-such as raising childhood immunisation rates-nobody is campaigning comprehensively, although individual groups are active. Fourthly, campaigns on some issues-for instance, reducing the harm done by alcohol-are failing dismally despite several groups working hard. Perhaps an organisation with larger interests and one that coordinated the other groups could be more successful. Finally, no one group seems to have an overall view of the myriad public health issues-not even the Faculty of Community Medicine, the professional associations, Health Concern, the College of Health, or the Health Education Council.

So, those at the meeting agreed, an organisation is needed, and this will need to be a new organisation. Those existing already are neither reaching decision makers nor impressing them with their arguments. The aim of the new organisation 
should be to ensure that whenever decisions are being made that might affect health-and there are a great many-the consequences to health are considered. Those decisions might be taken in the Cabinet, in any government department, in Brussels, in local government, in industry, or in the NHS. This is, of course, a very general aim, and several of those at the meeting thought that one more definite aim of the new organisation should be to work for the 38 specific goals for the year 2000 of the European office of the World Health Organisation. ${ }^{1}$

Indeed, some suggested that the new organisation might become a "British chapter" of the WHO initiative. Others had been impressed by the American and Canadian public health associations, which are large organisations with individual and group members. Without government support they produce authoritative documents on a wide range of public health topics and make sure that the information reaches decision makers. Whether or not they influence public policy is more debatable. Others preferred the model of the London Food Commission, which was founded by representatives from various relevant organisations. It takes an issue, forms a working party, produces a report, and then fulfils an educational and lobbying role. Another model might be the Maternity Alliance, which has succeeded in amplifying the voice of pressure groups concerned to improve the health of mothers and children. Agreement could not be reached at last week's meeting on the exact form of the new organisation or alliance, but a small planning group has been set up. It is expected to produce plans for a second meeting in October.

Certainly it would seem wrong to launch a new organisation without paying any attention to the thousands that already exist with some interest, no matter how small and tangential, in public health. Those organisations are too often failing, however, to move public health issues to the centre of the political stage, where they rightly belong, and some initiative is badly needed. Any new group that might be formed will be born into a hostile world and will need to be well equipped. It will need: the support of existing organisations; independence; access to high quality unbiased information and advice; and resources. All may be difficult to come by.

Assistant editor, $B M \mathcal{F}$

RICHARD SMITH

1 World Health Organisation Regional Office for Europe. Targets for health for all. Copenhagen: WHO, 1985.

\section{Lymphostatic disorders}

The lymphatic system plays a fundamental part in regulating the physiological environment by returning protein, cells, macromolecules, and fluid to the general circulation as well as removing metabolic byproducts, dying or mutant cells, microbes, and inorganic matter. ${ }^{\prime}$ Oedema may develop either from an excess of capillary filtrate with normal but overloaded regional lymphatics or from defective lymphatics with an unaltered lymph load. ${ }^{2}$ Stasis due to obstructed lymphatics (low lymph flow failure) is characterised by oedema fluid with a high protein content; it is seen, for example, after mastectomy. Overproduction of lymph, such as that associated with chronic venous insufficiency, causes high lymph flow failure-but this may also lead to lymph stasis through secondary damage to the lymphatic system. The term "lymphostatic disorder" has been suggested as a replacement for "lymphoedema" as it refers to all types of lymph stasis and overcomes the problem that there may be no clinically detectable oedema in some late stages of the condition. ${ }^{3}$

A lymphostatic disorder, then, is a progressive condition characterised by four main components: excess protein, oedema, chronic inflammation, and excess fibrosis. ${ }^{4}$ Fibrosis occurs late and reduces the perceptible pitting. Chronic peripheral lymph stasis produces thickened skin giving enhanced skin creases and deepened skin folds; it prevents the pinching of a fold of skin over the dorsal aspect of the toes or fingers (Stemmer's sign). ${ }^{5}$ Hyperkeratosis and verrucous and condylomatous changes are also features of longstanding lymph stasis, and if severe these are termed elephantiasis.

The patient's disabilities include pain, reduced mobility, and impaired function of a limb. Psychological disturbances also occur since the gross distortion of the tissues may affect the patient's social acceptance. Chronic lymph stasis commonly predisposes to infection and more rarely to the development of tumours (as in the Stewart-Treve's syndrome). Acute inflanmatory episodes, referred to as "cellulitis" or "erysipelas" may or may not be related to bacterial infection, but these invariably further damage existing lymphatics so compounding the problem. ${ }^{3}$

Lymphostatic disorders are considered rare, but we have no reliable epidemiological data on their prevalence. The reported incidence for lymph stasis after mastectomy varies from $9 \%$ to $63 \% .^{6-10}$ This variation is due to differing operations, whether or not the patient was irradiated, and the length of follow up-and it also depends on the definitions of severity or techniques of measurement. The diagnosis of chronic lymph stasis may usually be made clinically, though malignancy must always be excluded. Lymphography is widely used, but it provides only static non-functional anatomical information, and may be harmful. ${ }^{11}$ The best means of estimating lymphatic function is quantitative indirect lymphoscintigraphy. ${ }^{12}$

The management of lymphostatic disorders is unsatisfactory. The "grin and bear it" approach is as unacceptable as are mutilating surgical operations or amputations. Macrosurgery has no long term benefits, but advances in microsurgery are encouraging, particularly with lymphaticovenous anastomoses. ${ }^{13}$ No single operation is likely to be the answer in all cases. Drug treatment has been disappointing, and despite their widespread use diuretics are ineffective. The benzopyrone oxerutins reduces experimental high protein oedema, but its effect is slow and unpredictable. ${ }^{14}$ Physical treatment appears to be the most effective treatment; it comprises massage, compression with bandaging or pneumatically inflated sleeves, and gentle exercises. ${ }^{15}$ The improvement needs to be maintained by elastic hosiery, and the patient should be encouraged to use the limb normally. When the disorder is secondary to cancer vigilance for recurrence must be paramount. Infection must be treated promptly with antibiotics such as phenoxymethylpenicillin. Prophylactic attention to skin hygiene is essential, buc recurrent attacks of "cellulitis" may require long term treatment with antibiotics.

The aim of the recently formed British Lymphology Interest Group is to encourage clinical and scientific research programmes, to develop a platform for the dissemination of knowledge about lymphatic disorders, and to compile 